\title{
The Role of Risk Management in Enhancing the Process of Strategic Marketing Decision-Making: A Prospective Study of a Sample of Jordanian Industrial Companies
}

\author{
Ali Falah Al-zoubi ${ }^{1} \&$ Salman Mohammad Abulehyeh ${ }^{2}$ \\ ${ }^{1}$ Associate Prof of Marketing, Jordan \\ ${ }^{2}$ Assassinate Prof of Business Administration. Jordan \\ Correspondance: Ali Falah al-zoubi. Marketing Department, Faculty of business, Arab Amman University, \\ Amman, Jordan. E-mail: alzoubifali@yahoo.com
}

Received: January 10, 2017

Accepted: January 30, 2017 Online Published: February 22, 2017

doi:10.5539/ijbm.v12n3p94

URL: https://doi.org/10.5539/ijbm.v12n3p94

\begin{abstract}
The study aimed at identifying the role and importance of risk management in enhancing and managing the strategic and dynamic marketing decisions that relate to strategic problems of multi-dimensions and of great depth and complexity. This kind of decision requires in-depth research of the risks and the capacity for future analysis and discussions, which deal with all hypotheses and possibilities. Thus, the decision makers are critical resource for the company. Thus, it is necessary to stress on the importance of studying risk management and its role in enhancing the strategic marketing decision-making process, which is considered a way for companies to drive the future, which is the center of this study. In order to achieve the objectives of this study, a questionnaire was designed and distributed in person on a sample of managers of industrial companies in the Jordanian private sector.45 out of 65 distributed questionnaires were found to be valid. The data were statistically analyzed and the results showed that the strategic marketing decision makers in the industrial company realize the importance of risk management and employ it in the process of strategic marketing decision-making. However, the actual management or perfect investment of risk management in the industrial sector is still limited due to the existence of obstacles and limitations concerning managers and leaders and the available technical, information and material capabilities.
\end{abstract}

Keywords: risk management, strategic marketing decision-making, process, industrial companies, Jordan

\section{Introduction.}

The human exposes, in his public and private daily life, to the risks which cause psychological or/ and physical losses, and human characterized from other creatures of his ability to act and make decision, and in spite of this gift, but there are natural factors that may limit his ability and make him irrelevant. Hence, we can say that the risk is almost universal phenomenon linked to human daily life and activities. The human is also capable to make decision, but he then carries the results of these decisions ... due to lack of knowledge of what will happen in the future, he may face uncertainty of the validity of any decisions he wants to make, which forces him to think more than once while taking these decisions, and this may result in losing a chance or reluctance to participate it, whether this project was an investment or other.

The future of the organizations depends on the extent of realization and optimized investment of their resources and assets to increase their competitiveness and attempt to reinforce by protection and safety or the risk management that considers as one of the latest administrative concepts after realizing the importance of risk as an important element in achieving the company's objectives, and the strategic arms to achieve success and excellence. The real source of wealth in the world today is not the capital or the land, but is successes in addressing the risks, which consider a portal into a strategic success. The concept of risk management has been associated with the known economic base and multiple risks. As expressed by economists, these personal capabilities, talents and capacity shall be effectively exploited to achieve the objectives that society in general seeks to meet and to face the challenges and crises. As the human is the first circle of change in human society for achieving progress and overcome the dangers, companies and administrative leaders to deal efficiently and effectively in investing of risk management in the marketing strategic decision-making process so the company 
can reduce risks.

Because that the strategic marketing decision represents a selection of the field or activity carried out by the company and requires employing most of its assets and resources in order to obtain the greatest possible return within a certain period of time, this means the success or failure of companies to achieve their objectives, and thus, the companies will be more successful in their investment, if they are able to adopt a successful risk management.

\section{Research Methodology}

\subsection{Research Problem}

Fundamental differences have emerged in how to consider the concept of risk management and its importance and value. In developed societies, we find that there are greater and more attention to the issue of risk management and careful attention to how best to exploit it. This interest careful is less in developing societies in general. Controversy still exists about the true concept of risk management and that the whole subject has not been given due attention of researchers at the local and Arab levels, especially the Jordanian private sector companies, as these companies are still having difficulties in the scientific and practical linking between risk management and the strategic marketing decision. Where the decision-making process is of the most difficult tasks in the corporate governance process, because that the good administrative and leader success appears only after making a decision in difficult situations and crises faced by the company, and the making of scientific and rationality decisions requires reliance on facts and data to deal with the problem and take the safety and protection method in the decision-making process.In addition to that risk management is the missing link in business management researches and that the fundamental problem in risks is not in their existence or not, but the problem is that companies have not benefited from successful solutions available in the minds of managers.

\subsection{Research Questions}

Accordingly, the study was guided by the following research questions:

- What is the importance of using risk management in the strategic marketing decision-making process?

- What is the extent of using risk management in industrial companies?

- To what extent do the managers of industrial companies recognize the importance of using risk in the decision-making process?

- Is it possible to bridge the gap between the risk management in developed and developing countries and increase the competitiveness in the era of globalization and market openness?

\subsection{Importance of Research}

- Scientific Importance: it derives from the research benefit in the scientific field through its theoretical background, as risk management is a missing link in business management research in the developing countries including Jordan.

- Practical Importance: The research is one of the first researches, which study the relationship between risk management and decision-making process in the Jordanian private sector companies.

\subsection{Research Objectives}

In light of the study problem and the lack of studies in the field of risk management and strategic marketing decision-making, the research aims to achieve the following objectives:

- Attempt to move toward the modern structure of coping with risks.

- Employment of familiarity and knowledge of risk management and of strategic marketing decision-making in the development of preparation of the research methodology and to provide a modest contribution of a number of variables.

- Survey the extent of the significant direct correlation between the risks and the decision-making process adopted by the top management.

- Evaluation of risk management in the surveyed companies.

- The possibility of analysing the problem of not addressing the risks, the factors that cause this phenomenon, and developing methods to control it. 


\subsection{Variables of Research}

In order to determine the conceptual model of the study, two independent variables were adopted, which are Risk management (including inherent and sudden risks) and the strategic marketing decision-making process. (Figure1)

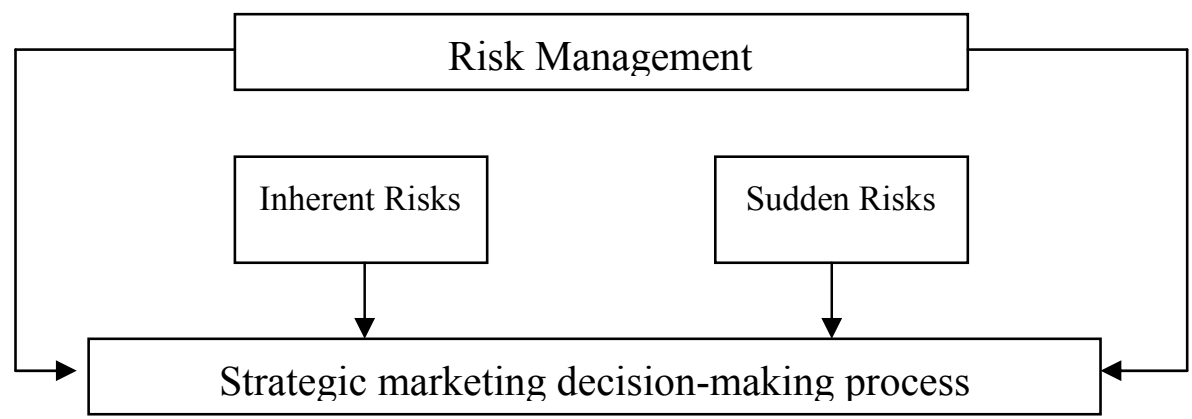

Figure 1. The research model

Source:( Designed by the researchers, 2016).

\subsection{The Research Hypotheses}

Based on the study variables, the following hypotheses are raised:

H1: There is a significant relationship between risk management and the strategic marketing decision-making process.

H1a: There is a significant relationship between sudden risks and the strategic marketing decision-making process.

H1b: There is a significant relationship between Inherent risks and the strategic marketing decision-making process.

\subsection{The Research Procedures}

The following paragraphs include the characterizations of study sample and delimitations, data collection, statistical analysis instruments:

\subsubsection{Research Design}

The current research problem was studied with a behavioral approach influenced by the Behaviorism. Regarding the field aspect, the researcher adopts the exploratory survey method in order to survey the views of the sample on the risk management and strategic marketing decision-making, as well as the descriptive and analytical approach to analyze the results of statistical tests and provide explanations on them .

\subsubsection{The Sample and Delimitations}

The study population consists of Jordan Cement Factories Company, Arab Potash Company, Jordan Paper \& Cardboard Factories Company PLC, Dar Al Dawa Pharmaceutical Products and Jordan Detergent Industries Co., representing the industrial sector in Jordan, because of their leadership in this sector and their privileged position in the domestic market, coupled with the diversity of resources and products. A purposive sample consists of 45 of managers, directors and heads of departments was selected for the purposes of data collection.

\subsubsection{Data Collection Tools}

Tools of collection data related to the theoretical side: the Arab and foreign sources and references, and discussion of some studies and results carried out in the framework of the research variables.

Tools of collection data related to the Practical side: the personal interviews with administrators from the private sector and a number of managers in the surveyed companies, as well as documents, records, publications and reports. The questionnaire was the main tool for data collection, and Likert scale was used to measure respondents' attitude to the study variables and many paragraphs on taking the strategic marketing decision.

\subsubsection{Statistical Data Analysis Tools}

Having developed a database on Set Graph program and SPSS Program, the following statistical analysis tools were used: 
- Mean: to determine the level of respondents' attitudes to the study variables.

- Standard Deviation: to measure of a spread of data around the mean.

- Spearman's Rank Correlation Coefficient: to determine the strength and direction of the relationship between the study variables.

- $\quad$ T Test: to determine if there is a significant linear relationship between the calculated variables.

\section{Theoretical Framework}

\subsection{Risk Management}

\subsubsection{Concept of Risk Management}

Risk management means the systematically and continuously understanding, identifying, providing and assessing the factors that threaten the organization's assets, capabilities, objectives and reputation, and trying to control them to avoid future crises for organizations. The most significant risks facing the organizations are as follows:

1- Risks affecting the company's products and clients.

2- Risks that threaten the company's reputation and credibility and impair the confidence of clients.

3- Risks that occur in the company's internal and external levels. (Ali Alzoubi,2016)

The duties and tasks of risk management can be identified by knowing the duties performed by the Manager of this department as he is in charge of the development of plans and strategies studied with high efficiency and implementing actions to prevent or reduce the risk occurrence and losses through the use of safety and protection means. These duties can be summarized as follows: (Ali Alzoubi, 2015)

- Identify and discover risks.

- $\quad$ Setting goals.

- Measure the risks.

- Comparison to choose the best means to manage risk.

- Implement the risk program.

- Assess and review the risk program.

The bodies that work within this administration and be associated with it are: security office which is responsible for ensuring the external safety, firefighting unit which is responsible for discovering and handling the dangers, and maintenance unit which is responsible for ensuring the continuation of the production process. (Abaza, 2002)

\subsubsection{Risk Types}

- $\quad$ Sudden Risks: Risks that occur unexpectedly without any warning and constitute a crisis, and are addressed through crisis management.

- Inherent Risks: the risks that are in the activity of the person or the purpose for which it provides. (Nonake and Taken chi ,2005)

\subsubsection{Objectives of Risk Management Plan}

- $\quad$ Minimizing the event risks.

- $\quad$ Removing the event risks.

- $\quad$ Transforming the event risks. (Nonake and Taken chi ,2005)

\subsubsection{Risk management Plans}

- Identify risk management methods, tools and techniques.

- Develop Plan A and Plan B for risks management.

- Development of integrated system for implementing risks management plans.

- Implement Plans.

- $\quad$ Continuously monitor the outputs. (Abaza, 2002)

3.1.5 Recent Trends in Risk Management 
3.1.5.1 Information Risk management: The world has called for a strategy of information risk management. Including the United States, which called on the private sector to cooperate with the US government, as well as cooperation in coordination to protect the security of the nation through a national strategy for the protection of information space that depends on:

- Reinforcement of laws to prevent and proceeding of aggressors in information and its domains.

- Laying a plant to understand the hidden results of threats and possible points of weakness.

- Improving procedures of the net of information and its branches.

- Reinforcement of trustworthy digital power usages.

- Contraction and strengthening the computer programmers against attacks and viruses.

- Improvement of information systems security and communication nets.

- Submitting the significance of the Federal Information Security Researches and its developmental programs.

- $\quad$ Submitting and insuring the origination systems of informatics. (Johnson and schools, 2002 )

\subsubsection{Competitive Risks Management}

Aims at decreasing the outcome costs on confronting the risks, or contracting the period to surpass it. The competitive risks management assists on glorifying the value of the organization, through:

- Employing a work-team with multi cognitive specializations to specify the profitable risks and submit suitable solutions.

- Saving accurate statistical information to find prophesying solutions for the profitable risks.

- $\quad$ Finding the profitable opportunities for the organization. There are methods to apply the management of competitive risks :

- Supporting the risks management of operations in the organization in specifying risks and the how of managing and dealing with them.

- Laying message for the organization and adopting a strategy within an integrated and comprehensive vision.

- Reinforcing contact between the higher administration risks management, and other management to understand the task of risks management, and decision - taking and objectives.

- Consisting work-teams to treat risks from the different domains of knowledge and science from inside and outside the organization to confront those risks.

- Training and developing work-teams to risk in how to deal with those risks.

- $\quad$ Laying accurate standards to measure and generalize their usage by those concerned with the matter.

- Effective participation in the teaching process from the previous lessons in managing risks. (As-Sibai', 2006).

The relationship of risks management with the administrations and departments of the company

Relationship of risks management with production and processes. From the most important ties between both administrations are the following :

- Risks management works to insure the administration or production against the possible incident dangers that may cause great substantial losses, affect directly on the financial position of the project, or may lead to its annihilation.

- Both administrations participate in carrying out programs of protection and peace.

- Risks management specific the means peace and protection inside the administration of production.

- Risks management continuously does inspection on warehouses of storage and filling to make sure of storing of raw materials in correct way protects its quality.

- $\quad$ Risks management does continuous control on stages of production. (Johnson and schools,2002)

Risks management relationship with human resources management. From the most important ties between these two administrations, are the following:

- $\quad$ Risks management may share with individual's management in choosing employees. 
- Both administrations participate in the estimation of suitable compensation for employees.

- Both administrations participate in programs of preparation and training, the matters that leads to development of the skill at individuals working in the project and increasing the ability at them in controlling some risks and totally shun them.

- Both administrations participate in specifying the traits that are granted to the employees in cases of disease, unemployment and infections resulting from work and retirement.

- Both administrations participate in carrying out the program of safety. (Polanyi, 2008)

The relationship of risks management with the management of financial affairs. From the most important ties between these two administrations, are the following:

- The financial administration provides the risks administration with detailed data prices, employment, lost time, damaged goods and averages of machines breaking-down; these are from the information that may share in decreasing expenditures.

- The administration shares in the account of insurances premium and following its payment systematically.

- The financial administration provides the administration of risks with financial lists in the form of estimating budgets of the expected risks in the future and the value of its administration costs.

- The financial administration provides the administration of risks with information including the value of raw materials, value of products, and the value of damage the matter that urges the administration or risks to review the followed mans in the unit of storing and work to treat them.( Dikeman J.B. ,2008)

The relationship of risks administration with the administration of financing:

- It was decided that both administrations share in taking the best decision by placing a new origin .... (a productive machine for example) in place of an ancient origin to increase production and limit losses resulting from the wasting time as a result of breaking down the origin of energy, damage, repairs, maintenance expenditures and decrease in the size of production.

- The administration of finance decides to pay for purchasing insurance and safety tools.

- If the industrial project followed the policy of self- insuring by confiscating reserve can be consisted by subtracting it, therefore both administrations cooperate to choose suitable investing canals. (A'bwi, 2006).

The relationship of risks administration with marketing and sales administration. The most important ties between both administrations are the following:

- At marketing products and transporting them to markets of distribution, those products may be exposed to damage, loss, or theft the matter, from which generates demand of the project with commitment of the emerging damages value from danger for the interest of the client in such a case. Both administrations cooperate on following a certain policy to transfer the burden of danger from the project to others by a purchasing document of a safety document from companies of insurance. (Leonard Barton, Doroth ,2005 )

Relationship of risks administration with public relations administration. From the most important ties between these two administrations, are the following:

- Decisions of purchasing administration to buy the concerned machines can be considered and the administration of risks provides them with accurate information about the machines and productive instruments equipped with means of safety, operate immediately to prevent occurrence of dangers and shun them, the matter by which lightening the financial burdens and achieving economic savings are generated.

- The project built on principles of peaceful administration is always productive of the best productions and self-restrained with high financial and economic ability.

- The human management with which the project deals with the employees leads to improving the administrative and the productive performance and guarantee loyalty of employees as a result of their feeling with promotion in their morale, the matter by which the project shuns risks of strike, muting and breaking down the production. (Leonard Barton, Doroth ,2005)

Relationship of risks administration with the legal administration. From the most important ties between these two administrations, are the following:

At emergence of conflict between the project and the company of insurance to carry out the compensation for the damage as a result of danger phenomenon achievement, in such a case the administration of risks 
should provide the legal administration with all legal pleadings built on technical points of view. In addition, the legal administration reviews the current insuring contracts programmed against risks. (Dikeman J.B. ,2008)

\subsubsection{Costs of Risks Management}

- Salaries and wages of employees in the corporation of insurance administration.

- Wages of experts and technicians who submit the technical consultations to the committee of risks administration.

- Cost of obtaining information, structures and instructions decided by the administration of risks in performing its works. (Burk Mike ,2009)

\subsubsection{Nature of Risks}

It is clear that two types of risks mains exposed to by numerous methods, as these risk had been divided in to: (Doven port, T.H. and Hansen, MT, 2007)

1. Non-economic danger. Its losses cannot be estimated, and cannot be compensated.

2. Economic danger. It is divided into :

- Dangers of speculation and decision - taking. Man creates them all by himself.

- Dangers with natural occurrence, whose occurrence leads to substantial losses, their types are :

- General dangers include :

- $\quad$ Living state (unemployment - depression- inflation).

- Political situation (wars - riot- revolts).

- $\quad$ Changes in nature (earthquakes - volcanoes - storms- floods).

- $\quad$ Particular dangers include: dangers of persons - dangers of property- dangers of civil responsibility. (A'bwi, 2006).

And generally results from the existence of danger in human life their permanent attempts for future planning, reaching and seeking promotion and progress. We notice that whenever the danger escorting a certain work became great, happiness at the individual becomes great when he attaints his wish...but, of course resulted from existence of danger the feeling of fear by the human from future, or expectation of failure, the matter that leads sometimes, the persona to lead positive defensive policies or adoption of negative policies ....there upon the danger escorting the process of decision-taking can be defined as follows :"It is the doubt that depends on data and previous statistics with actual and objective indications of danger, it is a hesitation state or uncertain of the results of the decision. So, we can define the degree of danger at time of decision - taking as follows :It is a moral scale of the hesitation state and uncertainty that affects the person or persons at time of decisions - taking concerning an incident or a certain phenomenon that concerns them". And in a statistical definition more accurate : the degree of danger is the degree of the lost trust. The degree of the lost trust $=1$ - the degree of trust". (Daft, Richard, 2010).

And the degree of trust of the statistical test an a sample from the community is the scale that assists us to accept or reject an incident or a phenomenon that can be generalized on the community or studying the correctness of a certain claim concerning the milestones of this community. It is clear from what had preceded that the scale of danger degree is nothing, but a general moral scale for the phenomenon that encircle decision-makers and affect - in a form or another - on their decisions and count the degree of danger in quantity is not possible, except if moral scales existed similar to benefit scales that are used in the mathematical economy. (As-Sibai', 2005).

\subsection{The Strategic Marketing Decision}

\subsubsection{How to Make the Strategic Marketing Decision}

Challenges that confront business companies are abundant in a world the competition is considered its basic characteristic, may be the growth and enlargement of horizon imposed the company administration to think in it and play an axial role in establishing the impact of those challenges in the domain of their decisions, for issuing the scientific and rational decisions requires the group of facts and data to solve the administrative problems by an intelligent scientific and objective method, therefore the decision- taking was fro the most difficult tasks that wait the leader or the manager in the company. But we can say, without any exaggeration, that leadership is decision - making and companies at their difference demand individuals enjoy attributes, cognitions, values and experience to reach the message that the company seeks translating it and directing it towards reality across thinking and aiming with the strategic marketing decision to response to specialties of the different environment 
within a comprehensive and piercing vision, the human intellect and thinking are still in the first position. For these occurring developments are ascribable to the outcome of human thinking. The available risks in the minds of managers at a form of intuition, experiences and thinking, did not gain an abundant chance of concern and did not invest the best investment in reinforcing and the administrative decision- making. (Bilal Alsakarneh, 2010) .

So it has to direct the thinking of companies to the factors that share in exploding the cognitive abilities of human resources. Because companies of the age always need the cognitive leader, who can take the correct decision in the appropriate time concerning the risks. The decision is considered the essence of the administrative process and its political means in achieving the objectives of the company (Ashama', 2009).

The decision in fact is a choice among a group of raised replacements to solve a certain problem, or a crisis, or operating a certain work after specifying the elements of strength and weakness of each replacement preparing for choosing the best replacement (As-Salem, 2010).But the strategic decisions are the decisions that specify on what the company will be in the future and its impact is including the organizational until such as the decisions related with the merging of the company, its size, its competitive position, or products and services they submit.

The responsibility of taking this type of decisions lies on the higher administration, mostly the higher administration has to lead the cognitive armament to take such type of decisions and so the cognitive storage for the leader or the manager with what he owns of information and data, and also abilities, intuition, thinking accumulated and innovative experiences, and ability of solving problems, in addition to all what preceded, the values affect and play a prominent role in the process of taking decisions and in the following domains (Ibrahim, 2011).

- $\quad$ Process of laying objectives.

- Process of developing replacements and choosing the suitable solution.

- Process of choosing techniques or the suitable means to carry out the decision.

- $\quad$ Process of following up and finding the suitable solutions of incidents and stands.

\subsubsection{Steps of the Process of Taking the Strategic Marketing Decisions}

The process of taking decisions is done in a continuous rotation with the continuation of the administrative marketing process itself, and most of scholars of administration agreed upon specifying practical steps of taking the decision as follows:

- $\quad$ Specifying the marketing problem that needs solution.

- Collecting information related with it.

- Different replacements are evaluated, and specifying traits and negatives of each of them

- Choosing the best replacements in light of the previous evaluation of the different replacements.(Ali Alzoubi,2015)

\section{Data Analysis and Hypothesis Testing}

\subsection{Data Analysis}

The researchers seek through data analysis and the discussion of the results to show the levels of responses of the research sample in respect of research variables, and to this end an appropriate statistical tools has been used (such as averages, standard deviations, frequencies and ratios).

\subsubsection{Analysis of the Responses Related to Sudden Risks}

Table 1 shows that $(81.54 \%)$ of the respondents are aware of the importance of the sudden risks represented in the information available in the company and its structures, and that $(7.17 \%)$ of the respondents were unsure of their answers, and (3.54\%) of the respondents strongly disagree to the importance of these risks, which resulted in a general average of (3.91) and a general standard deviation of (0.47).

\subsubsection{Analysis of Responses Related to the Potential Risks}

(36.92\%) of the responses confirmed that they are totally unaware of the importance of skills, experiences and capabilities possessed by individuals about the potential risks, and (36.92\%) of the respondents were unsure or neutral in their responses, which resulted in a general average of (2.08) and a general standard deviation of $(0.43)$ as shown in Table 2. 
Table 1. Relative frequency distribution, average and standard deviation of the respondents about the sudden risks $(\mathrm{N}=45)$

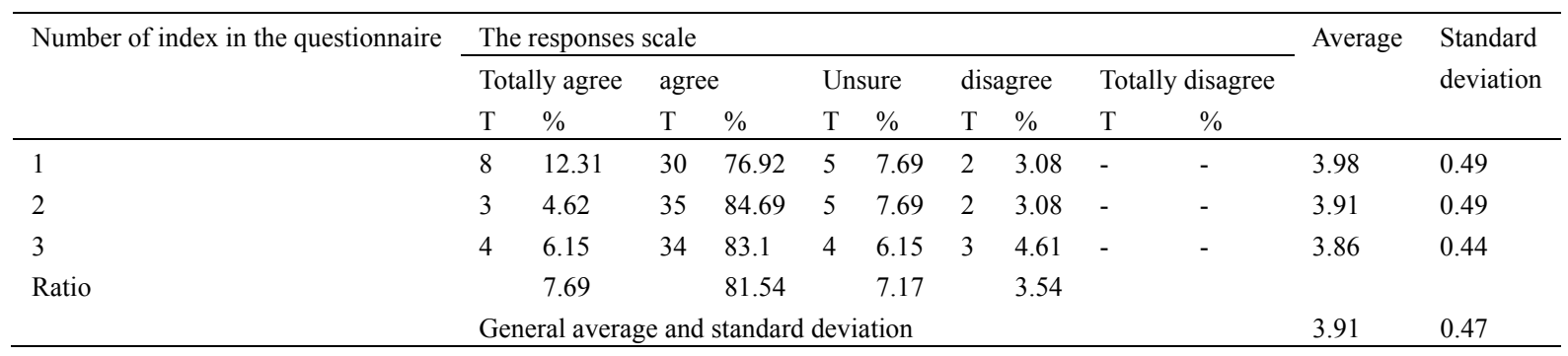

Table 2. Relative Frequency distribution, average and standard deviation of the respondents about the potential risks $(\mathrm{N}=45)$

\begin{tabular}{|c|c|c|c|c|c|c|c|c|c|c|c|c|}
\hline \multirow{3}{*}{$\begin{array}{l}\text { Number of } \\
\text { index in the } \\
\text { questionnaire }\end{array}$} & \multicolumn{10}{|c|}{ The responses scale } & \multirow[t]{3}{*}{ Average } & \multirow{3}{*}{$\begin{array}{l}\text { Standard } \\
\text { deviation }\end{array}$} \\
\hline & \multicolumn{2}{|c|}{ Totally agree } & \multicolumn{2}{|c|}{ agree } & \multicolumn{2}{|c|}{ Unsure } & \multicolumn{2}{|c|}{ disagree } & \multicolumn{2}{|c|}{ Totally disagree } & & \\
\hline & $\mathrm{T}$ & $\%$ & $\mathrm{~T}$ & $\%$ & $\mathrm{~T}$ & $\%$ & $\mathrm{~T}$ & $\%$ & $\mathrm{~T}$ & $\%$ & & \\
\hline 4 & - & - & - & - & 37 & 87.69 & 8 & 12.31 & - & - & 2.88 & 0.33 \\
\hline 5 & - & - & - & - & 8 & 12.31 & 37 & 87.69 & - & - & 2.12 & 0.33 \\
\hline 6 & - & - & - & - & 7 & 10.77 & 3 & 4.62 & 35 & 84.62 & 1.26 & 0.64 \\
\hline \multirow[t]{2}{*}{ Ratio } & & 7.69 & & 81.54 & 37 & 36.92 & 8 & 34.87 & & 28.20 & & \\
\hline & Get & al avera & and & ard dev & & & & & & & & \\
\hline
\end{tabular}

\subsubsection{Analysis of Responses on the Process of Decision-Making and Strategic Marketing}

Table 3 shows that $85.77 \%$ of the respondents agree on the optimal active role of the decision-making process of strategic marketing, which determines the fate of the company, and $(3.84 \%)$ of the respondents completely agree on that, and with the same percentage refuse or agree on that while $(6.53 \%)$ of the respondents were unsure of the importance of strategic marketing decision in determining the fate of the company, which resulted in a general average of (3.88) and a standard deviation in the amount of (0.48).

Table 3. Relative Frequency distribution, average and standard deviation of the respondents about the process of decision-making and strategic marketing $(\mathrm{N}=45)$

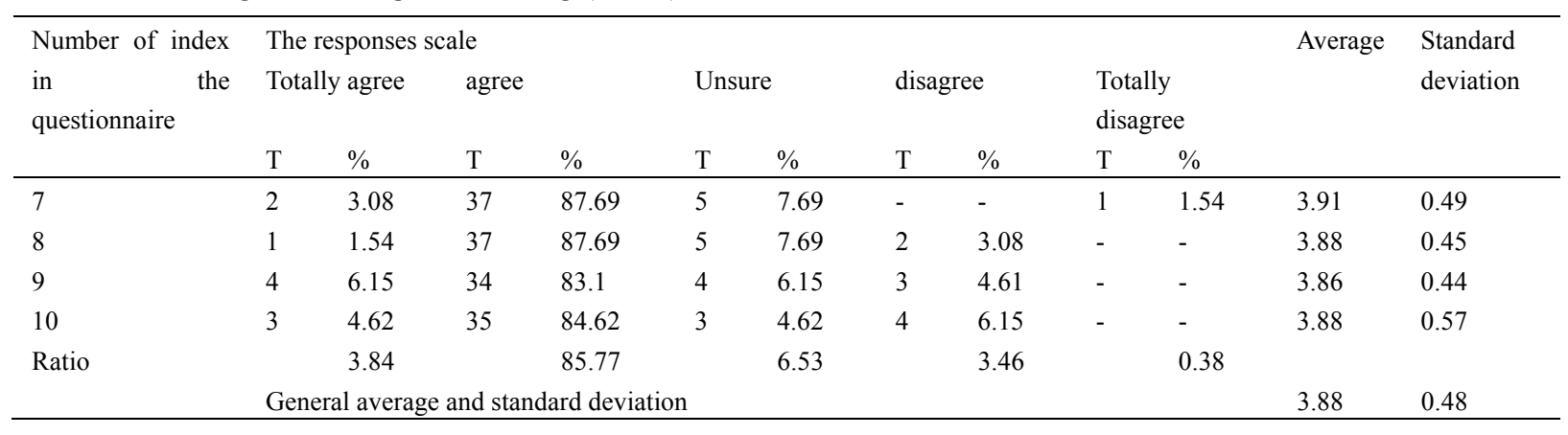

\subsection{Examining Hypotheses}

\section{-Examining the main hypothesis of the research}

For the purpose of testing the relationship between risk management and decision-making process of strategic marketing, the sub-hypotheses emanating from this hypothesis will be tested first using the Spearman rank correlation coefficient, and as shown below:

Examining the first sub-hypothesis (testing the relationship between sudden risks and the process of decision-making and strategic marketing)

By using the ranks of Spearman correlation coefficient to test the link and the relationship between these two variables, we found that the value of $\left(\mathrm{R}^{\mathrm{s}}=0.76\right)$, and the value of $\mathrm{T}$ (calculated) (8.90) which is the largest value 
of its Indexed value, which is (2.01) and this indicates the presence of a significant correlation between the sudden risks and the process of decision-making and strategic marketing. Table 4 shows the significance level ( $\mathrm{P}$ $<0.05)$ and degree of freedom (43).

\section{Examining the second sub-hypothesis (testing the relationship between potential risks and the process of} decision-making and strategic marketing)

Through the test of this hypothesis, the value of $\left(\mathrm{R}^{\mathrm{s}}\right)$ was $(0.65)$ and the calculated value of $\mathrm{T}$ was $(6.51)$, which is greater than the indexed amount (2.01). This indicates a significant correlation between these two variables.

\section{Examining the main hypothesis of the research}

For ascertaining the existence of a statistically significant relationship or not between risk management and the process of decision-making and strategic marketing, testing has been done using the Spearman rank correlation coefficient. The value of $\left(\mathrm{R}^{\mathrm{s}}\right)$ was $(0.70)$ and the calculated value of $\mathrm{T}$ was $(7: 46)$; a greater than the value of the two tables was (2.01). The result confirms and proves this hypothesis and its authenticity and the existence of significant correlative relationship between These two variables Where clear that risk management including Provisions of concepts, whether sudden or latent and through knowledge and information in the company or through the skills and expertise possessed by its directors her active role in strategic decision-making successful process and that make this company a position competitively unique position to face the difficulties and obstacles and challenges in today's world.

Table 4. Spearman rank correlation coefficient between the risk management and decision-making process and strategic marketing

\begin{tabular}{llll}
\cline { 2 - 4 } Variables & value (rs) & type (T) calculated & Relationship value \\
\hline Sudden risk & 0.76 & 8.90 & Morale \\
Risks inherent & 0.65 & 6.51 & Morale \\
Risk Management (collectively) & 0.70 & 7.46 & Morale \\
\hline
\end{tabular}

Abstract level ( $\mathrm{p}<0.05)$, and the degree of freedom (43)

\section{Conclusion and Recommendations}

\subsection{Conclusion}

Throughout what has been mentioned in the theoretical part and in the light of the results, the following conclusion has been listed:

1. Risk management is an essential tool to practice various administrative activities in corporations. The optimal strategic marketing decision-making helps at problem- solving, addressing challenges, and identifying the corporation's destination and future.

2. Most of the managers of the research sample agree about the importance of the corporation's data and information and its structures, with their all-sudden risks and the significant role in the corporation's future planning process.

3. There is a high ratio of research's sample managers unable to recognize the inherent risks, including the corporation's difficulties, obstacles, and challenges to achieve the planned purposes within competitive conditions.

4. Most of the managers of the research sample agree upon the significance of enhancing the strategic marketing decision process, which is connected to the corporation's destination, through following practical methods and planned steps to make such strategic decisions.

\subsection{Recommendations}

Regarding to the conclusion, the following recommendations were made:

1. The serious attention of the corporations towards risk managements and processes, whereas it is the base of saving technical and substantial resources, and support of competitive traits in the light of constant changes and challenges in business environment.

2. The managers of the industrial corporations in the research sample have to take into consideration the vital role not only of sudden risks including corporation's challenges, but also keeping attention to knowledge and experience about inherent risks of their personnel and risks effective role in identifying the corporation's destiny 
and subsistence.

3. Following practical and scientific tools and methods in the strategic marketing making decisions process related to the corporations future, starting by identifying the marketing problem, collecting data, alternatives and evaluating them, then testing the best alternatives through the strategic optimal decision.

4. The significance of switching the industrial concerns in the Jordanian Private Sector from increasing the capital and work quality to focus on increasing knowledge of risks and challenges.

5. Making benefit of university competence and higher education by giving them leader positions that can be more effective and competent in strategic marketing making decision process.

6. One of the recommendations specifically to industrious corporates is serious thinking of establishing internet networking to link Jordanian Private Sector corporates work in similar industries in order to exchange risks and conditions relations. These relations may decrease the cost hold by an individual company.

7. Studying risk management by using other forms.

8. It is significant to create new courses in order to teach risk management in official and private universities in the future.

\section{References.}

Ali, Z. (2015). The management of modern marketing, Dar maasyra for publication, Jordan

Ali, Z., \& Adel, A. (2016). Foundations and scientific assets in Business Administration, Dar Yazouri Publishing, Jordan.

AlSibaee, A. (2005). Risk Management (3), Cairo- Egypt, Ad-Dar AlArabia for publishing.

Bilal, A. (2010). Strategic planning, Dar maayra for publication, Jordan.

Burk, M. (2009). Risks management, everyone by sharing information.

Daft, R. (2010). Organization theory and design (4th ed.). West publishing co. New York.

Dikeman, J. B. (2008). Risks management moves from theory towards practice. Mot., 43(4).

Doven, P., \& Hansen, M. T. (2007). Risks management. Brief Risks management At Hewlett Packard.

Ibrahim, Y. (2001). Distinguish Secrets and Success Strategies, Cairo, Egypt, Islamic Publishing and Distributing.

Johnson \& Schools. (2002). Exploring corporate strategy (6th ed). Financial times, prentice. Hall, London, New York.

Khalil, A. S. (2009). Corporate Theory, Baghdad.

Leonard, B. D. (2005). Well sparing of Risks: Building and sustaining the sources of innovation. Boston. M.A. Harvard.

Moyyad, A. S. (2000). Corporate theory, Amman, Dar Wael for Publishing.

Nonake, \& Taken, C. (2005). The Risks Greeting Company, How Japanese, companies create the pynamics of innovation.

Polanyi, M. (2008). Personal Risks, toward a post. Critical philosophy. Rout ledge, London.

Zaid, A. (2006). Risk and Insurance Management. Amman-Jordan, Kunus AlMa'refa Publisher.

\section{Copyrights}

Copyright for this article is retained by the author(s), with first publication rights granted to the journal.

This is an open-access article distributed under the terms and conditions of the Creative Commons Attribution license (http://creativecommons.org/licenses/by/4.0/). 